increased serum F.D.P. levels in women with clinically significant menorrhagia, as compared with those in women without abnormal menstrual symptoms. Further studies being undertaken indicate that raised serum F.D.P. levels found in women with menorrhagia are often associated with increased levels of fibrin monomer complexes in the blood. Thus raised serum F.D.P. levels in women complaining of menorrhagia may be a manifestation of exaggerated intravascular microcoagulation associated with secondary fibrinolytic activity.-I am, etc.,

Liverpool Maternity Hospital,

H. K. BASU Liverpoo

1 Hallberg, L., Högdahl, A. M., Nilsson, L., and Scandinavica, 1966, 45, 320 .

\section{Serum Hepatitis Hazard in Biochemical} Control Sera

SIR,-We have found hepatitis associated antigen (H.A.A.) in two samples of com mercially produced human serum used a controls in biochemical tests. These are Hyland Q-Pak Chemistry Control Serum II batch no. 3655 M022A2 and Warner Chil cott Versatol Diagnostic Reagent batch no. 0089027. The antigen is present in high titre as shown by countercurrent electrophoresis, electron microscopy, and by ge diffusion. Identity can be shown in the las test with known positive antigens.

We have since tested several other batches of these manufacturers' products and 50 other samples of similar products with negative results.

In view of the obvious hazard to laboratory staff we strongly recommend that all such material should be tested for H.A.A. before use.-We are, etc.,

A. D. Evans

Public Health Laboratory

University Hospital of Wales.

KeIth Davies

\section{Antibiotic-resistant Gonococci}

SIR,-In your very useful leading article (18 December 1971, p. 696) you comment on the present halt in the increase of resistant gonococci in Britain and warn that this respite is likely to be only temporary. If this be so now is the time to take action to prevent a situation developing such as you describe in other parts of the world. But what action? We agree with your advice concerning treatment in the individual, but we think that more is needed. Unfortunately, however, the amount of useful advice which can be offered is limited by our ignorance.

We do not know enough about the two essential ingredients in the epidemic situation: the gonococcus and the population at risk. As to the gonococcus we could make a sizeable list of the relevant items which as yet are unknown, and as to the population it is now so heterogeneous and subject to rapid change that much we thought we knew is out of date. Clearly intensified bacteriological investigation and sociological study are called for. While awaiting these we would like to draw attention to the use of sensitivity testing not only to guide in the treatment of the individual and to monitor changes in the incidence of resistant strains but as a tool for epidemiological study. If the results of penicillin sensitivity tests are correlated, case by case, with information gained by clinician and social worker and the complete data analysed light is thrown on current epidemiological patterns and on the mechanisms of emerging resistance.

As an example of the value of such studies we refer you to our report ${ }^{1}$ on a study of penicillin-insensitive gonococci in the Bolton area in the months just prior to the introduction of high-dosage penicillin therapy in

1969. Among other observations we found a significant preponderance of insensitive strains in immigrants as compared with nonimmigrants, and also an apparent preponderance of insensitive strains in younger nonimmigrant females as compared with other indigenous groups. The latter finding we thought to be evidence that many young women were being treated elsewhere than in the clinic because, that being so, referrals would be mainly of those with resistant infections.

For analytical purposes we found that simple classification of strains by penicillin sensitivity was useful: sensitive (penicillin minimum inhibitory concentration $<0.015$ $\mu \mathrm{g} / \mathrm{ml}$ ); intermediate (M.I.C. $0.03-0.06$ $\mu \mathrm{g} / \mathrm{ml}$ ); and insensitive (M.I.C. $>0 \cdot 12 \mu \mathrm{g} /$ $\mathrm{ml}$ ). We encountered no highly insentitive strains but such a category would be desirable for strains of M.I.C. $>0.5 \mu \mathrm{g} / \mathrm{ml}$.

We provided evidence that penicillin M.I.C. is a sufficiently stable character of individual strains to be used epidemiologically in the way indicated. We believe that studies such as ours, on a greater scale, would provide results which would be very helpful in planning future control measures. -We are, etc.

P. S. Silver

Diagnostic Clinic, Health Department,

Bolton, Lancs

Silver, P. S., and Darling, W. M., British fourna

\section{Unusual Reaction to Trimethoprim} in Combined Therapy

SIR,-The use of a new drug, which associates a sulphonamide with trimethoprim, represents a therapeutic advance. This drug works on two consecutive levels of bacterial metabolism. and this diminishes the risk of acquired bacterial resistance. Soon after the drug came into use various side effects were reported, the most common being skin rashes.

I should like to report the following case in which a morbilliform rash appeared to be due to trimethoprim.

A 49-year-old woman had suffered from severe asthma since 1957. In February 1968 she had a thvroid nodule removed, and since then her asthma had been worse, with frequent attacks of status asthmaticus. Immunotherapy has been ineffective. She is also allergic to several drugs: aspirin, penicillin and aminopyrine and its derivatives.

On 22 January 1971 she became very dyspnoeic with wheezing and rhonchi, and had pus in the nose and sputum. She was put on sulfamethoxazole-trimethroprim: 400 $\mathrm{mg} / 80 \mathrm{mg}$ four times a day for 10 days. The therapeutic effect was good and pus disappeared both in nose and in sputum. On the tenth day a morbilliform rash appeared, localized to trunk and popliteal spaces, and she had joint pains. The administration of the drug was immediately stopped, and I prescribed $0.25 \mathrm{mg}$ betamethasone with $2 \mathrm{mg}$ dexchlorpheniramine in half dose three times a day for three days. The rash and arthralgias disappeared.

This observation resembles other reported cases, but, in this particular case, an interesting fact was mentioned by the patient. Two years before, she had an identical rash after having taken bamifylline (Trentadil) a bronchodilator which has in common with trimethoprim a pyrimidine nucleus.

Several weeks later the patient could take sulfamethoxazole without any reaction, and therefore I consider that in this case trimethoprim could be considered as responsible for the rash and arthralgia.

It seems that trimethoprim is seldom responsible for skin or systemic allergic reactions, but the possibility must be kept in mind when one prescribes the very useful combination of sulfamethoxazole-trimethoprim.-I am, etc., Paris

GEORgES M. HALPERN

\section{Rifampicin and Isoniazid and} Liver Function

SIR,-The experience of Dr. Satinder Lal and others (15 January, p. 148) on the effect of rifampicin and isoniazid (I.N.H.) on liver function is similar in a way to my own. I have found the rise of aspartate transaminase (SGOT) not to indicate significant abnormality of liver function and have naturally continued chemotherapy with rifampicin and isoniazid. I have, however, seen hepatotoxicity in patients receiving treatment for Mycobacterium tuberculosis infection with rifampicin and isoniazid when this is determined by measurement of bilirubin, alkaline phosphatase, and alanine transaminase (SGPT). The first indications have generally been symptomatic. Patients with these biochemical abnormalities, especially raised alanine transaminase, have generally felt unwell before biochemical detection of the abnormalities. The biochemical checks are carried out before and fortnightly after starting treatment.

A review of the experience of this clinic since 1969 showed that 26 patients had been treated with rifampicin and isoniazid up to early 1971. Of that number, eight (or $30 \%$ ) showed abnormality of liver function, indicated by raised bilirubin (more than $1 \mathrm{mg}$ / $100 \mathrm{ml}$ ), raised alkaline phosphatase (greater than $15 \mathrm{King}$ Armstrong units $/ 100 \mathrm{ml}$ ), and raised alanine transaminase (SGPT more than $40 \mathrm{~m}$. i.u. $/ \mathrm{ml}$ ). There was only one case of raised alkaline phosphatase alone. This was in a child of 6 years and the level was greater than 35 K.A. units. Treatment was continued without any adverse effect or any other abnormality. I have since been told that this is not unexpected in children and appears to be harmless. The alkaline phosphatase returned to normal values on cessation of therapy and the child has remained well thereafter. One case showed the bilirubin alone was raised. Here again treatment was continued and the values returned to normal eventually. There were no symptoms. In all the others there was abnormality of enzyme (SGPT) together with abnormality of either or both bilirubin and alkaline phosphatase. In these there were symptoms referrable to liver dysfunction such as anorexia, nausea, and vomiting. Also, 
ill defined right hypochondrial and epigastric discomfort was felt. However, these symptoms were sufficiently severe to demand cessation of therapy. They improved and subsequently disappeared soon after therapy with these drugs was suspended. So it appeared to us that abnormality of alanine transaminase was a good indication of hepatotoxicity in these patients.

These tests have now been adopted as routine in this clinic in all patients receiving therapy with rifampicin and isoniazid in any combination. It will be interesting to see whether patients showing abnormality of SGPT are also slow acetylators. This may be a good screening test for those who will be treated with this very effective combination and is to be investigated.-I am, etc.,

Chest Clinic,

Churchill Hospital,

C. O. ANAH

\section{Depressive Illness and Aggression in Belfast}

SIR,-I was most interested to read the paper by Dr. H. A. Lyons ( 5 February, p. 342) concerning depression and aggression in Ulster. However, I wonder what account has been taken of the effect of the disruption of general practitioner care on the referral of patients to hospital outpatients during the present troubles. It would seem to me that this might well have had an effect on the figures for the referral of depressive patients per se, but would be less likely to have affected the figures for suicide attempts. -I am, etc.,

Newcastle General Hospital.

J. R. ASHTON

Newcastle upon Tyne

\section{Bacteroides Infections}

SIR,-We read with interest the paper by Dr. Oonagh Tracy and her colleagues (29 January, p. 280) on "Lincomycins in the Treatment of Bacteroides Infections."

In their article they mention that they were unaware of any published clinical account of the use of this group of antibiotics in the treatment of such infections. At the Fifth International Congress of Chemotherapy held in Vienna in 1967 we described the case of a 55-year-old woman suffering from diverticulitis associated with bacteroides septicaemia, which responded satisfactorily to lincomycin.' The minimum inhibitory concentration of the organism for lincomycin was $0.25 \mu \mathrm{g} / \mathrm{ml}$. - We are, etc.

\section{A. M. GEDDES}

East Birmingham Hospital,

J. F. MUNRO

\section{Birmingham}

1 Geddes, A. M., Munro, J. F., Murdoch, J. McC., of the 5 th., and Burns, B. A., in Proceedings of the 5th International Congress of Chemo thor. 1, p. 361. Vienna, Wiener Medizinisch Akademie, 1967.

\section{Torsion of Testis}

SIR, - Your timely leader and the article by Di R. H. Chapman and Mr. A. J. Walton (15 January, p. 164) emphasize the problems of diagnosis of torsior of the testicle. My own approach to any patient referred with a diagnosis of epididymitis is to ask myself first if this could be either torsion or tumour. Torsion is common, is commonly overlooked, and is often misdiagnosed as epididymitis. The latter is the most frequent diagnosis in general practice, and in a small "epidemic" of torsions which I dealt with some years ago-some 35 cases in 2 months - the correct diagnosis was made only once by the general practitioner.

Having seen two patients referred as having appendicitis, who in fact had torsions, I was glad to see Mr. Thomas Moore's letter (5 February, p. 374). At first sight, the pain may be similar, but I find that it is of ten rather lower and more medial than is usual in appendicitis, and the signs of peritonitis are less marked than one would ex-

pect for the severity of the pain if it were caused by appendicitis.

As the congenital anatomical anomaly which makes torsion possible is in my experience always bilateral, I find it of value to examine the unaffected testicle. If the anomaly is present, the testicle can be turned easily through $180^{\circ}$ or more so that the lower pole is uppermost. The normal testicle tends to flip back at about $160^{\circ}$. This test, incidentally, is also of great value in cases of chronic or recurrent torsion or in those occasional individuals with longstanding testicular pain for which no cause is immediately apparent.

There is really only one disaster in exploration-namely, to explore a testicular tumour through a scrotal incision in mistake for a torsion. This, however, is another problem.-I am, etc.,

Department of Urology, Newcastle General Hospital,
New castle upon Tyne

D. M. ESSENHIGH

SIR,-I have read with interest the recent correspondence on this subject (5 February, p. 373) and would like if I may to make three further comments.

There is nothing new about manual reduction. About 16 years ago I reported case which I had successfully reduced and described how this should be attempted by the practitioner who first sees the case. This was the all-important point I made, as unless a fully-blown torsion is reduced within an hour or two of its onset it is probably a waste of time reducing it at all Long-term reviews have shown that most of those cases which were thought to have been successfully treated surgically ended up with atrophied testes.

My second point concerns diagnosis Torsion of the testicle is undoubtedly the commonest cause of pain and swelling in a young boy, but is by no means the only cause, as several of your correspondents have pointed out. Unfortunately so much publicity has recently been given to misdiagnosis of torsion that many young surgeons are exploring testes quite unnecessarily. I am afraid this has happened on several occasions in recent years on my own unit. That operation does no harm is no excuse for faulty diagnosis.

Finally, and most important of all, if one does explore a testis and if its viability is doubtful, for heaven's sake do not remove it! Even if one leaves a completely infarcted testis all that will happen is that it will atrophy. The slightest bit of healthy testi- cular tissue is probably better than nothing. One never knows what might happen to the other.-I am, etc.,

Ashford Hospital,

ROBIN BURKITT Ashford, Middx

1 Burkitt. R. British Medical fournal, 1956, 2, 345.

\section{Doctor-Patient Relationships}

SIR,-Dr. H. W. Ashworth's pessimismPersonal View (12 February, p. 437)astounds me. Here is a man who qualified when I did in 1944, who has lived through all the improvements affecting general practice in the last quarter of a century, who has the advantage moreover of working with good doctors in a university teaching practice, and who yet can say "popular opinion of the profession reaches a new low" and "In America the public hate the doctors while in this country the doctors hate the patients. It may not be long before our patients emulate their American cousins." My own view is almost diametrically opposed to his.

A more educated and literate public are certainly helping to dispel some of the mumbo-jumbo and black magic on which the profession has relied in the past to maintain its authority. This is surely a good thing because it helps to keep doctors alert and thinking. To explain the diagnosis, treatment, and prognosis of a serious medical condition to an educated patient, a doctor must really understand the condition himself. With better understanding of individual episodes of illness comes increasing wisdom, better medical care, and a b-tter doctor-patient relationship.

There are undoubtedly potential risks to this relationship in the modern trend towards group practice, and if the profession is not fully aware of these its public image could well deteriorate. The main danger is of doctors taking the easy way out and seeing any patients in the group who ask to see them instead of training all patients to attach themselves to one doctor only. Many patients do not mind which doctor they see. but doctors who have looked after their own patients consistently know that this is better for patients as well as doctors.

If these risks are borne in mind, however, the many advantages of group practice to the doctor such as adequate leisure, freedom from non-clinical work, and regular contact with colleagues for discussion will help to improve standards of medical care, and tension between the public and the professinn is likely to decrease.

All of us are biased by our experience and I personally have found that patients nowadays are generallv more considerate in their demands than they were in the early years of the National Health Service. I don' think I am alone in this feeling.-I am, etc.

DeNis CRADDOCK

South Croydon

\section{Unfair to Baboons}

Sir.-The recent book $^{1}$ and newspaper arricles in the Sundnv Times (September 1971) hy Jane Goorall have made it quite clear that some primates are animals of intelligence with a social order and family sense. They abpear to nossess many emotions in common with Homo sapiens. How 